\title{
Correction to: Advanced Practice Providers
}

\author{
Randi L. Collinson
}

\section{Correction to: K. A. Gross (ed.), Advanced Practice and Leadership in Radiology Nursing, https://doi.org/10.1007/978-3-030-32679-1}

There were two misspellings in Fig. 1.1 in the original version of the book in Chap. 1. The spelling errors have now been corrected.

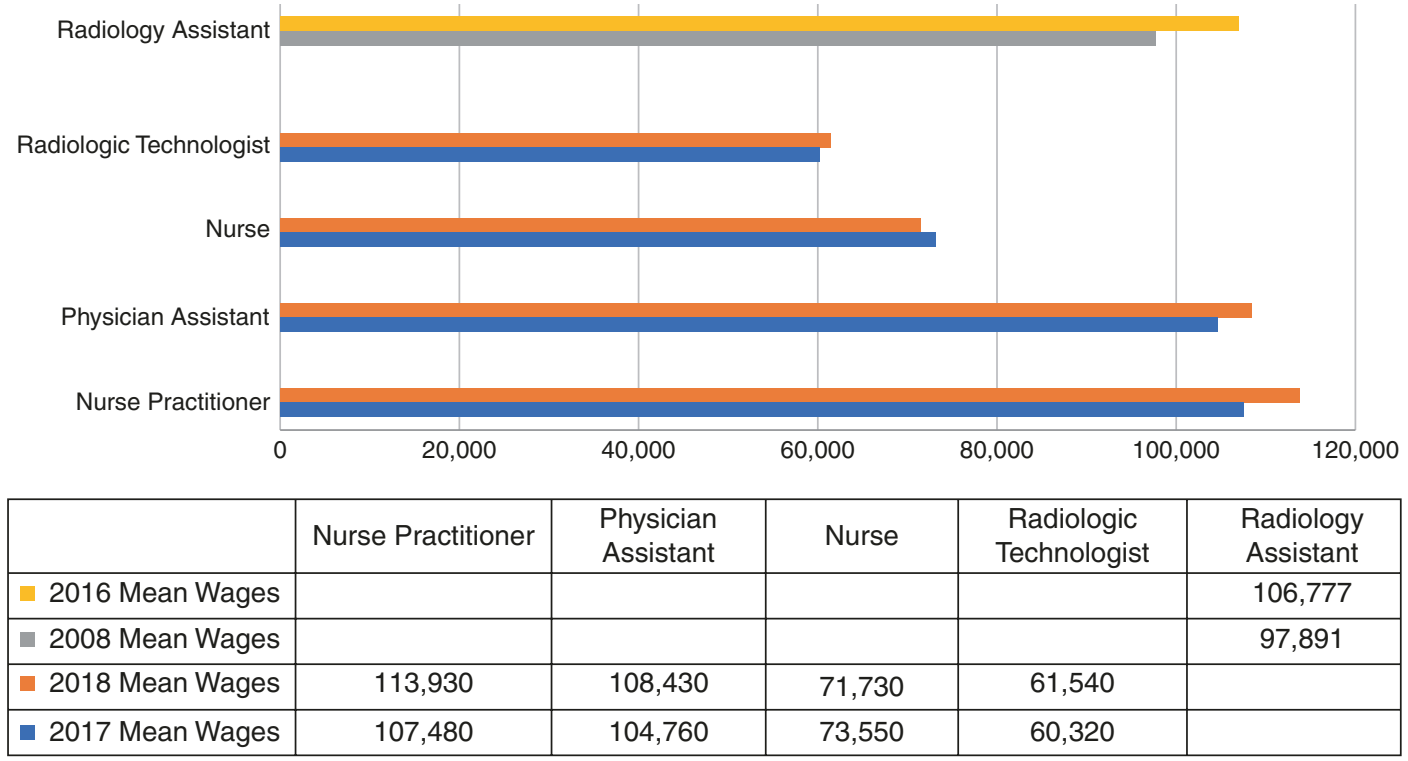

Fig. 1.1 Medical professionals in the United States. (Source: From refs. [42-44]) 